УДК 556.31:628.112.2

DOI: https://doi.org/10.17308/geology.2020.4/3129

Поступила в редакцию: 27.11.2020

Принята к публикации: 01.12.2020

Опубликована онлайн: 18.12 .2020

\title{
Оценка гидрогеохимической ситуации на участке водозабора «Никольский» (г. Лиски, Воронежская область)
}

\author{
Ю. М. Зинюков \\ Воронежский государственный университет \\ Университетская пл., 1, 394018, Воронеж, Российская Федерация
}

\begin{abstract}
Аннотация
Введение: В стратегическом плане развития города Лиски Воронежской области в качестве одной из главнейших проблем названа проблема улучшения качества жизни населения. При этом важнейшими задачами, требующими решения в рамках улучшения качества жизни, являются: обеспечение бесперебойного снабжения водой жителей города; обеспечение полного соответствия качества питьевой воды действующим нормативам. В настоящее время водоснабжение г. Лиски осуществляется следующими водозаборами: водозабор «Богатое» составляет 5.14 тыс. м³/сутки; водозабор

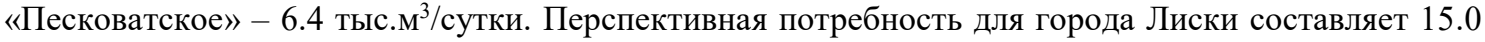
тыс. ${ }^{3}$ /сутки. Строительство водозабора «Никольский» вызвано дефицитом и прогрессирующим ухудшением качества питьевой воды, добываемой на существующих водозаборах.

Методика и обсуждение результатов: Участок водозабора расположен в 5 км восточнее х. Никольский и имеет протяженность около 5 км вдоль правобережья реки Дон. В качестве перспективных водоносных подразделений были определены: современный аллювиальный горизонт, имеющий гидравлическую связь с р. Дон, апт-сеноманский терригенный горизонт и девонский терригенный комплекс. Данные горизонты находятся в определенной гидравлической взаимосвязи. На настоящий момент времени на участке водозабора имеет место неблагоприятная гидрогеохимическая ситуация со значительным превышением содержаний железа (в четвертичном горизонте до 18 мг/л), с его повышенным содержанием в водах девонского комплекса до 3.2 мг/л. В водах четвертичного горизонта фиксируется постоянный рост показателя жесткости до 12 мг-экв/л. Повышенной жесткостью отличаются и воды девонского комплекса до 10.9 мг-экв/л. В четвертичном горизонте отмечены повышенные значения марганца до 1.02 мг/л. Основными поставщиками данных элементов являются природные минеральные и органические соединения и комплексы. В современном горизонте воды в настоящий момент характеризуются и значительным превышением по таким показателям как цветность и мутность, что связывается с опытными откачками и вероятным вовлечением в дренируемый поток коллоидов и различных органических соединений.

Bblвoды и рекомендации: Главными причинами ухудшения гидрогеохимической ситуации на исследуемом участке является возрастание уровня отдельных показателей качества подземных вод за счет нарушения естественного режима формирования химического состава и сложившегося геохимического равновесия. При откачках, особенно если они носят хаотический характер, резко изменяются гидрогеодинамические условия. В зону искусственного дренирования потока вовлекаются смежные структуры с повышенным содержанием кальция и магния, основных компонентов определяющих жесткость вод. Для выработки рекомендаций по оптимизации работы водозабора из существующих скважин с возможным дополнительным обустройством новых скважин требуется проведение работ мониторингового характера в полевых условиях (за режимом дебита, уровня и химического состава), по сути решающих задачи эксплуатационной разведки.
\end{abstract}

Контент доступен под лицензией Creative Commons Attribution 4.0 License.

\footnotetext{
凹 Зинюков Юрий Михайлович, e-mail: zinykov209@mail.ru 
Ключевые слова: проблема водоснабжения, показатели качества воды, химические вещества, водозабор.

Для циитирования: Зинюков Ю. М. Оценка гидрогеохимической ситуации на участке водозабора «Никольский» (г. Лиски, Воронежская область) // Вестник Воронежского государственного университета. Серия: Геология. 2020. №4. С. 75-80. DOI: doi.org/10.17308/geology.2020.4/3129

\section{Введение}

Город Лиски является административным центром Лискинского района Воронежской области с населением более 55 тысяч человек. Город расположен на левом берегу реки Дон, на территории междуречья притоков Хворостань и Икорец.

В географическом отношении территория городского поселения относится к южной окраинной части Окско-Донской низменности. Правобережье относится к восточному склону Среднерусской возвышенности.

Левобережье представляет собой сильно расчлененную овражно-балочной сетью равнину. Рельеф левобережья характеризуется сочетанием высоких плоских водоразделов с довольно редкими балками, глубина которых не превышает 20 м. Овраги и промоины имеют подчиненное значение. Правобережье представлено расчлененной овражно-балочной сетью с максимальными отметками до 200 м. Овраги и балки глубокие, большой протяженности. Поверхность правобережья расчленена различного рода западинами и рытвинами.

В стратегическом плане развития городского поселения города Лиски на период до 2020 года в качестве одной из главнейших проблем названа проблема улучшения качества жизни населения. При этом важнейшими задачами, требующих решения в рамках улучшения качества жизни являются: обеспечение бесперебойного снабжения водой жителей городского округа на основе увеличения мощности водозаборных станций; проектирование, строительство и ввод в эксплуатацию новой и реконструкция действующих водозаборных станций; достижение уровня потребления воды, соответствующего установленным нормам; обеспечение полного соответствия качества питьевой воды действующим нормативам и, соответственно, обеспечение жителей города питьевой водой надлежащего качества [1].

В настоящее время водоснабжение г. Лиски осуществляется водозаборами МУП «Водоканал»: водозабор «Богатое» составляет 5.14 тыс. м $^{3}$ ссутки; водозабор «Песковатское»- 6.4 тыс.м ${ }^{3} /$ сутки. Перспективная потребность для города Лиски составляет 15.0 тыс. $\mathrm{m}^{3} /$ сутки (Отчет о проведении геологоразведочных работ по изысканию нового источника водоснабжения для г. Лиски Лискинского муниципального района Воронежской области (Воронеж, ООО НПФ «Воронежгидрогеоэкология», 2010 г.).

Строительство водозабора «Никольский» вызвано дефицитом и прогрессирующим ухудшением качества питьевой воды, добываемой на существующих водозаборах г. Лиски.

Участок водозабора расположен в 5-5.5 км восточ- нее х. Никольский и имеет протяженность около 5 км вдоль правобережья реки Дон. Территория представлена водораздельным склоном с террасовидными площадками шириной 100 и более метров, и поймой шириной до 800 м. Участок расположен на непахотных и луговых землях. В паводковый период пойма затапливается.

В качестве перспективных водоносных подразделений были определены: современный аллювиальный горизонт, имеющий гидравлическую связь с р. Дон, апт-сеноманский терригенный горизонт и девонский терригенный комплекс. Данные горизонты находятся в определенной гидравлической взаимосвязи.

Суммарный водоотбор в количестве 15.02 тыс куб.м/сутки по проектным расчетам должен обеспечиваться за счет естественных ресурсов мелового и девонского комплексов, их естественных запасов и запасов четвертичного горизонта, а также привлекаемых ресурсов - поверхностных вод р. Дон. Подсчет запасов подземных вод на участке выполнен методом математического моделирования. Геофильтрационное моделирование для подсчета запасов выполнено ООО «Ингеолком» г. Москва (Гриневский С.О.).

Потенциальных источников загрязнения планируемых к эксплуатации водоносных подразделений на участке геологического изучения выявлено не было. На период проведения разведочных работ качественный состав подземных вод, в целом, соответствовал целевому назначению. Исключение составлял показатель содержания железа общего, превышавшего норматив в отдельных пробах до 1.7 ПДК. В целом, для питьевой воды систем централизованного водоснабжения города Лиски характерным является повышенные показатели общей жесткости и железа [2].

\section{Методика}

Водозабор «Никольский» имеет трехъярусное площадное и глубинное строение (рис. 1). Первый ярус (ряд) ПД-3 состоит из пяти скважин, оборудованных на современный аллювиальный водоносный горизонт (скв.11a, 11b, 11c, 11p-э, 12p-э). Данный ряд скважин расположен наиболее близко к р. Дон. Второй средний ярус (ряд) ПД-2 состоит из восьми скважин, оборудованных на девонский водоносный комплекс (скв. 8а, $8 \mathrm{~b}, 9 \mathrm{a}, 9 \mathrm{~b}, 10 \mathrm{a}, 8 \mathrm{p}-э, 9 \mathrm{p}-э, 10 \mathrm{p}-э)$. Третий ярус (ряд) ПД1 , самый дальний от $p$. Дон, состоит из пяти скважин, оборудованных на апт-сеноманский водоносный горизонт (скв. 1a, 1b, 1p-э, 2p-э, 3p-э).

В основу анализа гидрогеохимической ситуации легли материалы буровых работ и результаты опробования эксплуатационных скважин водозабора, а также экспертное заключение, составленное автором данной статьи в декабре 2018 года. 




Рис.1. Схема расположения скважин водозабора «Никольский».

[Fig. 1. The layout of the wells of the Nikolsky water intake.]

\section{Характеристика продуктивных} водоносных подразделений

Современный аллювиальный горизонт характеризуется гидрокарбонатным кальциевым гидрохимическим типом (такой же тип отмечался и в 2008 г.). За счет гидрокарбонатов формировалась и формируется основная доля общей минерализации подземных вод, при значениях сухого остатка 408-530 мг/дм³ концентрации гидрокарбонатов составляли 360-451 мг/дм ${ }^{3}$. Основным типообразующим катионом являлся кальций с содержанием 112-132 мг/дм³ (табл. прил. №3 Отчета ООО НПФ «Воронежгидрогеоэкология», 2010 г.). Содержание общего железа не превышало ПДК и было характерным для природных вод (0.05-0.26 мг/дм $\left.{ }^{3}\right)$. Глубина опробования скважин (11p-э, 12p-э) - 11-16 м.

В период наблюдений 2013, 2014 гг. и в период последнего опробования (лето, середина и конец ноября 2018 г.) гидрогеохимическая ситуация изменяется следующим образом. Отмечается значительный рост концентраций железа от 1.5-2 мг/л до 13-18 мг/л (скв.11с (5ф); скв.25p (5y)), постепенное, но стабильное возрастание величины общей жесткости - 7.5 до 12 мг-экв/л, фиксируется рост концентраций марганца от нормы (менее 0.1 мг/) до 0.97-1.02 мг/л (скв.11а (5c); скв.25p (5у)). Во всех скважинах резко возросли такие показатели как цветность и мутность.

\section{Апт-сеноманский водоносный горизонт}

Воды данного горизонта отличаются наиболее стабильным химическим составом. Все показатели соответствуют нормативам (за единичными разовыми не значительными отклонениями по жесткости и железу (скв.1а (5б); скв. 2p-э (5г)).

\section{Девонский водоносный комплекс}

Подземные воды ястребовской свиты в 2005-2006 гг. характеризовались низкой жесткостью 3.8-5.8 мгэкв/л, низким содержанием железа - 0.10-0.16 мг/дм ${ }^{3}$.

Девонский водоносный комплекс на участке водозабора отличается чрезвычайной пестротой строения и фациального состава водовмещающих и водоупорных образований, невыдержанностью их мощностей и глубин залегания. Так, например, в скважине №9а чередуются отложения саргаевского, чаплыгинского, ястребовского, мулинского, ардатовского, воробьевского возраста. По литологическому строению в разрезе сменяют друг друга известняки, глины, песчаники, глины, известняки, глины. Такая пестрота толщи отличается соответствующим своеобразием условий формирования химического состава за счет выщелачивания и растворения различных минералов и органических комплексов, в том числе минералов кальция, марганца и железа. Любое нарушение гидрогеодинамического режима может приводить к изменению характера массопереноса в девонском комплексе и в смежных с ним горизонтах.

В водах девонского комплекса в период 2013-2018 гг. во всех скважинах зафиксированы стабильно немного повышенные значения общей жесткости (относительно норматива) - преимущественно - 7.5-9 мгэкв/л. При этом в скв.9р-э (5е) (2013 г.) и в скв. 10а $(5$ н) (2014 г.) показатель общей жесткости был ниже норма- 
тива ПДК. Вместе с тем, в скв. 10р-э (5п) в 2013 г. показатель жесткости составлял 10.2 мг-экв/л, в скв. 24pэ (5ж) в 2015 г. - 9.6 мг-экв/л. Также в водах девонского комплекса в 2018 г. во всех скважинах фиксируются повышенные концентрации железа до 3 мг/л (скв.10а (5н)). В ряде скважин в 2013-2015 гг. содержание железа соответствовало норме (скв.5е, 5ж, 5н). В то же время в 2013-2015 гг. в скв. 5л, 5м, 5 п уже отмечалось повышенное содержание железа.

Также следует отметить, что в протоколах анализов воды указан такой параметр как сухой остаток, в то время как для гидрогеологов важен такой показатель как общая минерализация. С учетом повышенных концентраций гидрокарбонатов минерализация будет отличаться более повышенными значениями в сравнении с сухим остатком. Также в протоколах химических анализов проб воды из девонских скважин за 2018 г. не указаны (не определены) такие компоненты как магний и натрий, которые относятся к основным типообразующим элементам, а магний - определяет еще и жесткость воды.

При этом необходимо акцентировать внимание на том, что неполнота аналитических определений показателей химического состава подземных вод, связанная с различными подходами к оценке состава питьевых подземных вод со стороны органов Госэпиднадзора, исходящих только из экологических подходов, и организаций геологического профиля - не всегда позволяет проводить полноценную гидрогеологическую оценку состояния гидрогеосферы любой исследуемой территории. В данном случае, речь идет о том, что не всегда определяются основные макрокомпоненты химического состава (гидрокарбонаты, кальций, магний, натрий, калий), которые определяют гидрогеохимический тип вод и условия миграции других элементов.

\section{Обсуждение результатов}

Сравнивая основные типообразующие компоненты, формирующие минерализацию вод в различных гидрогеологических подразделениях, можно сделать следующие выводы.

Кальций. В наибольшем количестве встречается (как до устройства водозабора, так и после его устройства) в современном аллювиальном горизонте, почти всегда превышая величину 100 мг/дм³ . В меньше степени кальций содержится в апт-сеноманском горизонте, как правило, в концентрациях, не превышающих 100 мг/дм³ ${ }^{3}$ В водах девонского комплекса его содержание близко содержанию в водах четвертичного горизонта.

Гидрокарбонаты. В наибольшем количестве встречаются в современном аллювиальном горизонте, почти

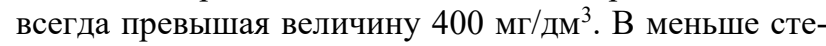
пени гидрокарбонат-ион содержится в апт-сеноманском горизонте, как правило, в концентрациях, не превышающих 250 мг/дм³ . В водах девонского комплекса его содержание, преимущественно, находится в пределах 250-350 мг/дм ${ }^{3}$.
Данные компоненты химического состава определяют повышенную жесткость подземных вод на участках с их высоким содержанием. Это природные концентрации, обусловленные постоянным присутствием в горизонте минералов карбоната кальция и других.

Содержания ионов магния и натрия больше носят подчиненный характер. Высокие природные концентрации таких типообразующих анионов как сульфатион и хлор-ион характерны для вод девонского комплекса. Особенно это касается сульфатов, которые иногда играют доминирующую роль в формировании общей минерализации. Хлориды местами имеют повышенные значения и в четвертичном горизонте. Сульфатные кальциевые минералы также способствуют повышению уровня жесткости подземных вод в девонском водоносном комплексе.

В целом, на настоящий момент времени на участке водозабора имеет место неблагоприятная гидрогеохимическая ситуация со значительным превышением концентраций железа (в четвертичном горизонте до 18 мг/л), с его повышенным содержанием в водах девонского комплекса до 3.2 мг/л. В водах четвертичного горизонта фиксируется постоянный рост показателя жесткости до 12 мг-экв/л. Повышенной жесткостью отличаются и воды девонского комплекса до 10.9 мгэкв/л. В четвертичном горизонте отмечены повышенные значения марганца до 1.02 мг/л. Основными поставщиками данных элементов являются природные минеральные и органические соединения и комплексы. В современном горизонте воды в настоящий момент характеризуются и значительным превышением по таким показателям как цветность и мутность, что связывается с опытными откачками и вероятным вовлечением в дренируемый поток коллоидов и различных органических соединений.

Наиболее благополучными в гидрогеохимическом отношении выглядят воды апт-сеноманского горизонта (за исключением единичных отклонений). Хорошим качеством отличаются воды данного горизонта и в х. Никольском, где все показатели соответствуют норме.

\section{Выводы и рекомендации}

Главными причинами ухудшения гидрогеохимической ситуации на исследуемом участке является возрастание уровня отдельных показателей качества подземных вод за счет нарушения естественного режима формирования химического состава и сложившегося геохимического равновесия. При откачках, особенно если они носили хаотический характер, могли резко изменяться гидрогеодинамические условия. В зону искусственного дренирования потока вовлекаются смежные структуры с повышенным содержанием кальция и магния, основных компонентов определяющих жесткость вод. На исследуемом участке это, преимущественно, кальций. При этом существенно нарушается геохимическое равновесие водного раствора. В целом, 
жесткость подземных вод характеризуется как довольно стабильный показатель, если гидрогеодинамические условия сильно не изменяются. При стабилизации гидрогеодинамической структуры потока стабилизируется гидрогеохимическая структура (обстановка). Существенное возрастание показателя жесткости, безусловно, связано с трансформацией потока в зонах искусственного дренирования.

Для выработки рекомендаций по оптимизации работы водозабора из существующих скважин с возможным дополнительным обустройством новых скважин требуется проведение работ мониторингового характера в полевых условиях (за режимом дебита, уровня и химического состава), по сути решающих задачи эксплуатационной разведки. Рекомендуется организация мониторинга количественных и качественных показателей подземных вод в рамках изучения единой природно-технической системы «подземные воды - технические сооружения водозабора» $[3,4]$. В этом случае можно надеяться на положительное решение данной проблемы, при строгом упорядочении работы водозабора.

Устройство сооружений по водоподготовке могло бы решить данную проблему при отсутствии фактического дефицита дебита. Однако простое наращивание мощностей водозаборных сооружений может в еще большей степени осложнить гидродинамику и как следствие дополнительное осложнение гидрогеохимической ситуации.

Конфликт интересов: Автор декларирует отсутствие явных и потенциальных конфликтов интересов, связанных с публикацией настоящей статьи.

\section{ЛИТЕРАТУРА}

1. Стратегия социально-экономического развития городского поселения город Лиски Лискинского муниципального района Воронежской области на период до 2020 года. Совет народных депутатов городского поселения города Лиски. $2011.33 \mathrm{c}$.

2. Прожорина Т.И., Куролап С.А., Гребенникова О.А. Геоэкологическая оценка состояния централизованного хозяйственно-питьевого водоснабжения малых городов Воронежской области // Вестник Удмуртского университета. Серия Биология. Науки о Земле. Т.29. Вып.2. 2019. С.213-220.

3. Зинюков Ю.М. Теоретико-методологические основы организации мониторинга природно-технических экосистем на основе их структурно-иерархических моделей // Труды научно-исследовательского института геологии Воронежского госуниверситета. Вып.28. Воронеж: Изд-во Воронеж.ун-та, 2005. 164 с.

4. Королев В. А. Мониторинг геологических, литотехнических и эколого-геологических систем. Москва, КДУ, 2007. $416 \mathrm{c}$.

UDC 556.31:628.112.2

DOI: https://doi.org/10.17308/geology.2020.4/3129

ISSN 1609-0691

Received: 27.11.2020

Accepted: 01.12.2020

Published online: 18.12 .2020

\title{
Assessment of the hydrogeochemical conditions at the Nikolsky water intake (Liski, Voronezh Region)
}

\author{
Yu. M. Zinyukov ${ }^{凶}$ \\ Voronezh State University 1 Universitetskaya pl., Voronezh 394018, Russian Federation
}

\begin{abstract}
Introduction: Among the key aims listed in the strategic plan for the development of Liski in the Voronezh Region is the need to improve the living standards in the town. In order to do this, two major tasks have to be completed: ensuring regular water supply and ensuring full compliance of the quality of drinking water to the existing standards. At present, the water supply in Liski is provided by two water intakes: the Bogatoe water intake provides 5.14 thousand $\mathrm{m}^{3} /$ day and the Peskovatskoe water intake provides 6.4 thousand $\mathrm{m}^{3} /$ day. The long-term requirement in Liski is 15.0 thousand $\mathrm{m}^{3} /$ day. The construction of the Nikolsky water intake was necessitated by a shortage and a progressive deterioration in the quality of drinking water produced at the existing water intakes in Liski.
\end{abstract}

The content is available under Creative Commons Attribution 4.0 License.

$\bowtie$ Yuri M. Zinyukov, e-mail: zinykov209@mail.ru 
Methodology: The water intake site is located $5 \mathrm{~km}$ east of Nikolsky village and occupies and area of about $5 \mathrm{~km}$ along the right bank of the Don River. The following were identified as promising aquifers: the modern alluvial aquifer, which has a hydraulic connection with the Don River, the Aptian-Cenomanian terrigenous aquifer, and the Devonian terrigenous system. There is a certain hydraulic relationship between these aquifers. At the moment, the hydrogeochemical conditions at the water intake are unfavourable, with a significant excess of iron (up to $18 \mathrm{mg} / \mathrm{l}$ in the Quaternary aquifer and up to $3.2 \mathrm{mg} / \mathrm{l}$ in the waters of the Devonian system). The waters of the Quaternary aquifer register a constant increase in hardness (up to 12 $\mathrm{mg}-\mathrm{gE} / \mathrm{l}$ ). The waters of the Devonian system are also characterized by increased hardness (up to $10.9 \mathrm{mg}-$ $\mathrm{gE} / \mathrm{l}$ ). Increased concentrations of manganese of up to $1.02 \mathrm{mg} / \mathrm{l}$ were also registered in the Quaternary aquifer. The main source of these elements are natural mineral and organic compounds and systems. In the modern aquifer, the waters are currently characterized by a significant excess in terms of colour and turbidity, which can be accounted for by pumping tests and the likely introduction of colloids and various organic compounds in the drained water.

Conclusions: The main reason for the deterioration of the hydrogeochemical conditions in the studied area is an increase in the level of certain indicators of groundwater quality due to the violation of the natural regime of the formation of the chemical composition and the existing geochemical equilibrium. During the pumping process, especially if it is chaotic, the hydrogeodynamic conditions change dramatically. Adjacent structures are involved the zone of artificial drainage. These structures have increased concentrations of calcium and magnesium, the main components that affect the hardness of water. In order to develop recommendations for optimizing the operation of water intake from the existing wells as well as for constructing additional wells, it is necessary to monitor the workflow in the field (the flow rate, its level, and chemical composition), i.e. to perform an appraisal survey.

Keywords: water supply problem, water quality indicators, chemicals, water intake.

For citation: Zinyukov Yu. M. Assessment of the hydrogeochemical situation at the Nikolsky water intake (Liski, Voronezh Region). Vestnik Voronezhskogo gosudarstvennogo universiteta. Seriya: Geologiya = Proceedings of Voronezh State University. Series: Geology, 2020, no. 4, pp. 75-80. DOI: doi.org/10.17308/geology.2020.4/3129

Conflict of interests: The authors declare the absence of obvious and potential conflicts of interest related to the publication of this article.

\section{REFERENCES}

1. Strategiya sotsial'no-ekonomicheskogo razvitiya gorodskogo poseleniya gorod Liski Liskinskogo munitsipal'nogo rayona Voronezhskoy oblasti na period do 2020 goda. Sovet narodnykh deputatov gorodskogo poseleniya goroda Liski. [The strategy of socio-economic development of the urban settlement of the city of Liski, Liskinsky municipal district of the Voronezh region for the period until 2020. Council of People's Deputies of the urban settlement of the city of Liski]. 2011, 33 p.

2. Prozhorina T.I., Kurolap S.A., Grebennikova O.A. Geoekologicheskaya otsenka sostoyaniya tsentralizovannogo khozyaystvenno-pit'evogo vodosnabzheniya malykh gorodov Voronezhskoy oblasti [Geoecological assessment of the state of centralized drinking water supply in small towns of the Voronezh region]. Bulletin of the Udmurt University. Biology series. Earth Sciences, v. 29, issue 2, 2019, pp. 213-220.

3. Zinyukov Yu.M. Teoretiko-metodologicheskie osnovy organizatsii monitoringa prirodno-tekhnicheskikh ekosistem na osnove ikh strukturno-ierarkhicheskikh modeley [Theoretical and methodological foundations of the organization of monitoring of natural and technical ecosystems on the basis of their structural and hierarchical models] Trudy Nauchno-issledovatel'skogo Instituta Geologii [The work of the Research Institute of Geology], Voronezh, VSU Publ., vol. 28, 2005, 164 p.

4. Korolev V. A. Monitoring geologicheskikh, litotekhnicheskikh i ekologo-geologicheskikh sistem [Monitoring of geological, lithotechnical and ecological-geological systems]. Moscow, KDU, 2007, 416 p.
Зинюков Юрий Михайлович - кандидат технических наук, доцент, заведующий кафедрой гидрогеологии, инженерной геологии и геоэкологии, Воронежский государственный университет, Воронеж, Российская Федерация;

E-mail: gidrogeol@mail.ru;

ORCID https: orcid.org/0000-0001-8465-0139

Автор прочитал и одобрил окончательный вариант рукописи.
Yuri M. Zinyukov - PhD in tech, associate professor, head of the department of hydrogeology, engineering geology and geoecology, Voronezh State University, Voronezh, Russian Federation; E-mail: gidrogeol@mail.ru; ORCID https: orcid.org/0000-0001-8465-0139

Author have read and approved the final manuscript. 